\title{
Redes Sociales Visuales: Caracterización, Componentes y posibilidades para el SEO de Sitios Intensivos en Contenidos
}

\author{
Raquel Herrera
}

\section{Lluís Codina}

Recibido: 9 de septiembre de 2015

Aceptado: 28 de septiembre de 2015

\section{Resumen}

Caracterización, funciones y componentes de las redes sociales visuales. Presentación de una matriz de análisis de redes sociales visuales y aplicación de la misma a un análisis comparativo de las tres principales de tales redes: Pinterest, Tumblr e Instagram. Caracterización de los sitios intensivos en contenidos y vinculación de las redes sociales visuales al SEO de esta categoría de sitios, entre los que destacan los cibermedios, a través de la documentación multimedia que generan estos sitios y el rol especialmente destacado que juegan en este aspecto redes como las analizadas en este trabajo.

\section{Pallabras clave}

Redes Sociales Visuales (RSV), Posicionamiento Web (SEO), Sitios Intensivos en Contenidos (SIC), Documentación Multimedia, Pinterest, Tumblr, Instagram

\section{Visual social media: description, components and SEO possibilities for content-heavy websites}

\section{Abstract}

Description, functions and components of visual social media. Presentation of an analysis matrix for visual social media, which is applied in a comparative analysis of the three main social networks of that kind: Pinterest, Tumblr and Instagram. Description of content-heavy websites and of the link between visual social media and SEO in this category, highlighting that digital newspapers generate a significant volume of multimedia content which are promoted by visual social media as those analyzed in this article.

\section{Keywords}

Visual Social Media (RSV), Search Engine Optimization (SEO), Content-heavy websites (SIC), Multimedia Content, Pinterest, Tumblr, Instagram

http://dx.doi.org/10.5209/rev CDMU.2015.v26.50627 


\section{INTRODUCCIÓN}

El primer objetivo de este trabajo lo constituye presentar una propuesta de caracterización de las redes sociales visuales, para lo cual primero ofreceremos una definición operativa y después procederemos a describir y caracterizar estas redes de forma sistemática utilizando una matriz de análisis que presentaremos también.

El segundo objetivo de este trabajo es vincular las redes sociales visuales con el SEO (Search Engine Optimization) de lo que denominamos Sitios Intensivos en Contenidos. Para ello, presentaremos así mismo otros estos dos conceptos, a saber, el ya mencionado de sitios intensivos en contenidos y el de SEO.

Pero antes que nada, debemos aclarar que, aunque actualmente todas las redes sociales tienden a ser visuales, en este trabajo nos centraremos en aquellas que lo son de una forma eminente por utilizar las imágenes como forma privilegiada de difundir contenidos. Para ello, presentamos nuestra propuesta de definición de redes sociales visuales (RSV):

Las redes sociales visuales son aquellas que sirven como plataforma y generan comunidad en base a compartir imágenes. Estas imágenes pueden ser estáticas, como fotografias o gráficos o en movimiento como vídeos o animaciones

\section{Definición I - Redes sociales visuales (RSV)}

Además, en este artículo nos centraremos en las redes Pinterest, Tumblr e Instagram. En primer lugar por ser las más importantes desde el punto de vista de su implantación social, y en segundo lugar por su capacidad de impacto potencial en el SEO de los sitios intensivos en contenidos, y entre ellos, en particular para los cibermedios.

\section{CONTEXTO}

Como ya hemos señalado, la existencia de esta redes sociales visuales especializadas, lo cierto es que resulta perfectamente posible publicar fotografías y vídeos en redes sociales generalistas como Facebook y Twitter. De hecho, las publicaciones que incluyen imágenes son las que suscitan mayor interés e incluso implicación (engagement) de las audiencias en términos publicitarios.

Los datos recopilados por la consultora Socialbakers en marzo de 2014 en base más de treinta mil páginas de Facebook procedentes de todo el mundo señalan que hasta un $75 \%$ del contenido primario en estas eran fotografías (respecto a un $10 \%$ de enlaces), y que las publicaciones más compartidas (un $87 \%$ ) eran también fotos (respecto a un $4 \%$ de enlaces). 


\section{Primary Type of Content Posted by Facebook Pages Worldwide, March 2014 \\ $\%$ of total}

\section{Photo}

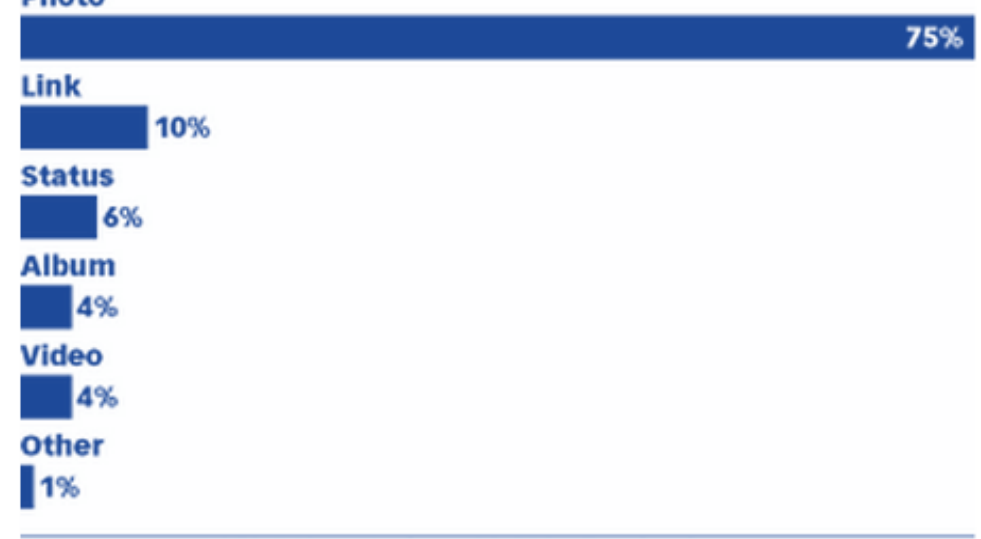

Note: among 1,253,840 posts from 30,000+ Facebook pages

Source: Socialbakers.com as cited in company blog, Acril 8, 2014

172115 wwweMarketer.com

\section{Most Shared Posts from Facebook Pages Worldwide, March 2014 \\ $\%$ of total}

\section{Photo}



Link

$4 \%$

Album

$4 \%$

Video

$3 \%$

Status

$2 \%$

Note: among the top $10 \%$ of posts in raw interactions from $30,000+$ Facebook pages

Source: Socialbakers.com as cited in company blog. April 8, 2014

172116

wwweMarketer.com

Figuras 1 y 2. Principal tipo de contenido compartido (foto, enlace, estado, álbum, vídeo, otros) y publicaciones más compartidas (foto, enlace, álbum, vídeo, estado) en Facebook, marzo 2014. Fuente: Socialbakers, vía emarketer.com (http://www.emarketer.com/Article/Photos-ClutteringYour-Facebook-Feed-Herersquos-Why/1010777/1)

Cuadernos de Documentación Multimedia Vol. 26.

Página 5 
Asimismo, Twitter llevó a cabo un estudio en 2014 para analizar los factores que podían afectar a la implicación de los usuarios en Twitter, examinados a través de los retuits relativos a los siguientes temas: televisión, noticias, música, gobierno y política, y deportes.

Durante el transcurso de un mes, analizaron los contenidos de más de dos millones de tuits enviados por usuarios estadounidenses con cuentas verificadas. Se observaron los retuits en relación a los siguientes aspectos medibles: URLS con fotos y vídeos, citas, tuits con números y hashtags; y se compararon con el promedio de retuits de esas mismas cuentas durante el mismo periodo temporal.

Los resultados del estudio indican que la implicación entendida a través de los retuits aumentaba notablemente al incluir fotografías:



Figura 3. Resultados totales correspondientes a los principales tipos de contenidos (hasthag, tuit con números, cita, URL de vídeo o de foto) retuiteados en Twitter, marzo 2014. (Al hacer clic en el gráfico original se accede a una pestaña que permite consultar el mismo gráfico según temas de interés televisión, noticias, música, gobierno y política, y deportes-). Fuente: Twitter (https://blog.twitter.com/2014/what-fuels-a-tweets-engagement) 
Por otro lado, con la información actualizada por las propias compañías, Instagram ya supera a Twitter en el número de cuentas activas: 300 millones en el caso de Instagram, y casi veinte millones menos en el caso de Twitter. La aplicación de fotografía para móvil que Mark Zuckerberg compró en 2012 posee tantos usuarios como usuarios activos, mientras que casi la mitad de los usuarios de Twitter no parecen estar activos.

Lo cierto es que, si bien menos extendidas, otras redes sociales visuales se multiplican y acumulan usuarios. Además de Instagram, en su último Mapa de redes sociales (creado originalmente por el exdirector infográfico del diario Boston Globe, Chiqui Esteban en abril de 2014 y continuado en 2015 por Rafel Höhr, editor gráfico de Prodigioso Volcán) para el congreso iRedes (http://www.iredes.es/mapa/) destaca como redes de "fotografía y vídeo" los ejemplos fotográficos de Imgur (130 millones), Flickr (92 millones) o Fotolog (33,5 millones); así como los videográficos de DailyMotion (120 millones), YouTube (1.000 millones) o Vimeo (170 millones).

Cabe señalar que redes sociales que el mencionado mapa de iRedes considera como generales, esto es, Tumblr (420 millones) y Pinterest (70 millones), se entenderían mejor como "redes sociales visuales" de acuerdo con nuestra definición presentada más arriba.

SEO y Sitios Intensivos en Contenidos

A continuación, proponemos las definiciones correspondientes a los otros dos conceptos con los que vamos a trabaja aquí, los de SEO y sitios intensivos en contenidos.

SEO1: Originalmente, el término SEO corresponde a las siglas de la expresión inglesa Search Engine Optimization, es decir, Optimización para Buscadores. En este sentido, consiste en el conjunto de operaciones llevadas a cabo para optimizar la visibilidad de contenidos publicados en la web a través de los motores de búsqueda.

SEO2: En una segunda variación, SEO corresponde a Search Experience Optimization, es decir, Optimización de la Experiencia de Búsqueda. Aunque para nosotros, SEO corresponde sin problemas a ambas acepciones (no son excluyentes), la segunda es la que preferimos adoptar en este trabajo, por lo tanto es lo que para nosotros significará aquí, si no indicamos lo contrario.

\section{Definición II - SEO1 y SEO2}

Reciben esta definición aquellos sitios cuya actividad natural genera grandes volúmenes relativos de información o contenidos. Este concepto se entiende mejor por comparación con los sitios que deben generar contenidos de una forma extra a sus actividades naturales o de negocio. Las tres categorías más importantes de SIC son: los cibermedios, los museos y las universidades. Lo más significativo de esta clase de sitios es que no necesiten desarrollar estrategias adicionales (aunque pueden hacerlo, si lo desean) para disponer contenidos para sus sitios web respectivos, puesto que de forma "natural" forma parte de sus actividades la producción de contenidos de calidad y de interés público.

\section{Definición III - Sitios Intensivos en Contenidos (SIC)}

Con el grupo de las tres definiciones presentadas, podemos proponer ahora la relación triangular que, en el modelo que proponemos nos permite relacionar los tres conceptos de una forma unificada, como estrategia 
de visualización de la información de los sitios intensivos en contenido, en un doble sentido, hacer visual (RSV) y hacerla visible (SEO).

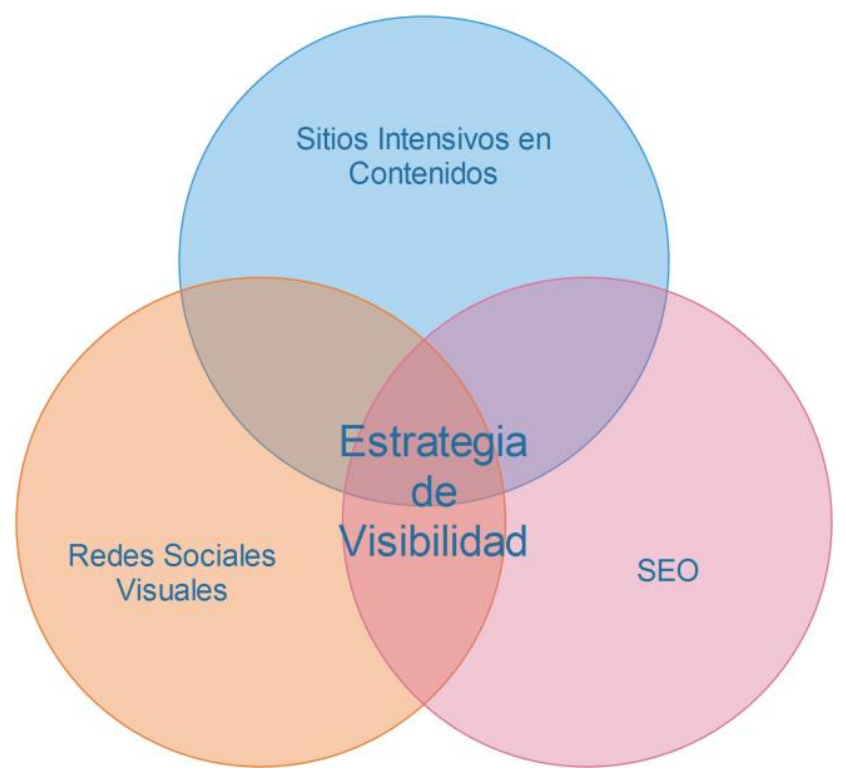

Diagrama 1: Estrategia de Visibilidad con RSV

La explicación de la relación anterior es la siguiente: por su naturaleza y funciones, los SIC son altamente susceptibles de generar de forma "natural" documentación audiovisual. Por su parte, las RSV son plataformas especializadas en difundir documentación audiovisual, y por último, la visibilidad o SEO, tanto en el sentido 1 como en el 2 (ver definición) se beneficia tanto del tráfico como de la hipermedialidad que proporcionan las RSV.

Por todo ello, las RSV son especialmente interesantes en el ámbito de la Documentación Multimedia por su doble valor: por un lado para atraer tráfico web y por el otro para apoyar acciones de SEO, en especial de los sitios intensivos en contenidos, porque como ya hemos indicado, éstos últimos, de forma "natural" tienden a producir contenidos, en los cuales cada vez abunda más la documentación audiovisual, tanto en forma de fotografías como vídeos. Esta es una evolución que se puede constatar de forma fácil en los tres tipos de sitios SIC más característicos: Cibermedios, Museos y Universidades.

\section{RSV: MATRIZ DE ANÁLISIS}

Nos centramos de nuevo en las RSV. En este apartado presentamos el sistema de análisis que aplicaremos a las tres redes sociales objeto de este estudio y que están experimentando un mayor auge: Pinterest, Tumblr e Instagram, a fin de poder caracterizarlas siguiendo un modelo sistemático. 
En concreto, para caracterizar cada una de las redes sociales visuales, utilizaremos el sistema de análisis basado en la siguiente matriz:

\begin{tabular}{l|l|l|}
\hline N & Parámetro & Dato \\
\hline $\begin{array}{l}\text { Datos de negocio } \\
\text { Incluyendo lugar, fecha, fundadores y propietarios actuales. Asimismo se } \\
\text { especifica el número de usuarios, el valor y posicionamiento de la red, y su } \\
\text { modelo de negocio. }\end{array}$ & Descripción \\
\hline 2 & $\begin{array}{l}\text { Elementos visuales } \\
\text { Estas redes articulan sus contenidos en torno a soluciones visuales características } \\
\text { y significativas, propias de cada red. }\end{array}$ & $\begin{array}{l}\text { Capturas de } \\
\text { pantalla y } \\
\text { descripción }\end{array}$ \\
\hline $\begin{array}{l}\text { Elementos } \\
\text { estructurales } \\
\text { Para este parámetro } \\
\text { utilizamos hasta 5 } \\
\text { dimensiones } \\
\text { distintas. }\end{array}$ & $\begin{array}{l}\text { 3.1. Origen de las imágenes: ¿proceden del propio sitio } \\
\text { web, de otros sitios web, pueden subirse desde el } \\
\text { ordenador? }\end{array}$ & $\begin{array}{l}\text { Descripción } \\
\text { loc. Recuperación de las imágenes: ¿dónde se buscan y } \\
\text { localizan imágenes?, ¿cómo se buscan y localizan, es } \\
\text { decir, qué criterios pueden utilizarse para recuperarlas? }\end{array}$ \\
\hline $\begin{array}{l}\text { 3.3. Clasificación de las imágenes: ¿de qué formas se } \\
\text { clasifican? }\end{array}$ & $\begin{array}{l}\text { 3.4. Funciones de red social: ¿qué elementos propios de } \\
\text { una red social general presenta la red visual analizada: } \\
\text { seguimiento; compartir, enviar y comentar contenido } \\
\text { dentro de la red visual o en otras redes o sitios web? }\end{array}$ \\
\hline $\begin{array}{l}\text { 3.5. Sistema de recomendación: ¿̇se recomienda } \\
\text { contenido en el propio sitio web, en otros, a través del } \\
\text { correo electrónico? }\end{array}$ \\
\hline
\end{tabular}

Una vez presentado el sistema procedemos a aplicar el mismo a las tres redes en las que se centra nuestro trabajo para poder llevar a cabo una caracterización sistemática de cada una de ellas.

\section{PINTEREST}

Pinterest es una aplicación web y móvil que, de acuerdo con sus creadores, ofrece una herramienta de descubrimiento visual (visual discovery), con capacidad para recopilar, compartir y almacenar información.

\section{Datos de negocío}

Pinterest nace en EEUU en marzo de 2010 de la mano de Ben Silbermann, Paul Sciarra y Evan Sharp. Actualmente la empresa está administrada por Cold Brew Labs y financiada por un pequeño grupo de emprendedores e inversores con capital de alto riesgo. 
Según el último estudio de la consultora Semiocast, el número de usuarios de Pinterest asciende a más de 70 millones mundiales, con predominio femenino y estadounidense. El sitio ocupa la posición 26 en el tráfico web según Alexa, y tiene un PageRank de 9/10.

El modelo de negocio se basa en el alta gratuita y el funcionamiento como escaparate virtual de productos, así como en el uso de los datos que comparten los usuarios libremente por parte de las empresas de márketing, y que pueden aprovecharse mediante las herramientas Pinterest Business y Pinterest Analytics.

\section{Elementos visuales}

Los elementos destacados de Pinterest son:

- Las imágenes o pines.

- Los tableros para clasificar pines.

- El feed de inicio que ejerce de página de inicio para pines y tableros propios y ajenos.

\section{El pin}

El pin es la unidad mínima de Pinterest. El sistema no almacena las imágenes como si se tratara del disco duro de un ordenador, sino el enlace a una determinada imagen.

Cada pin presenta diversas opciones de añadir (pin it) compartir (enviar) o "me gusta" (corazón), así como de añadir comentarios:

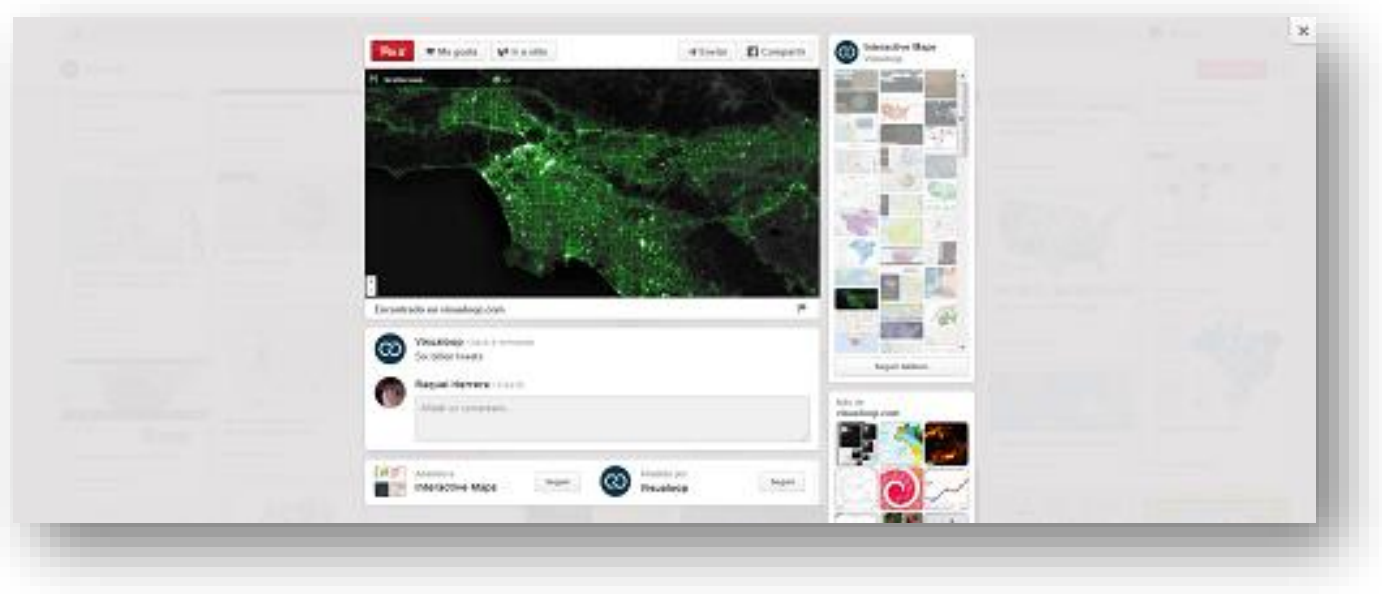

Figura 5. Pin "Six billion tweets". La imagen procede de un reportaje publicado en el sitio de actualidad infográfica Visualoop. Los administradores de Visualoop han "guardado" la imagen en el tablero Interactive Maps de su perfil de Pinterest. Fuente: Pinterest (http://www.pinterest.com/pin/129830401733705599/).

\section{El tablero}

Los pines pueden clasificarse en distintos tableros, públicos o privados. A través del perfil propio, los tableros pueden administrarse individualmente, o invitar a otros usuarios a pinear. Los tableros pueden modificarse y renombrarse como se desee, desplazando el orden de aparición de los pines en ellos. No se pueden crear subtableros dentro de los tableros. 
El número de tableros es ilimitado, pero si un tablero se crea público luego no puede hacerse privado (sí al revés).



Figura 6. El tablero Interactive Maps de Visualoop en Pinterest. Fuente: Pinterest (http://www.pinterest.com/visualoop/interactive-maps/).

Feed de inicio

El feed es la página de inicio de Pinterest. En el mismo, aparecen los elementos clave para utilizar Pinterest:

- En el extremo superior se encuentra la barra de búsqueda de imágenes.

- En el extremo superior derecho aparece el nombre del usuario. Al desplegar esta pestaña se puede acceder tanto al perfil propio, como a las notificaciones relativas a noticias de la red, avisos del perfil propio y mensajes intercambiados con otros usuarios.

- En el extremo superior izquierdo, debajo de la barra de búsqueda, se halla la posibilidad de invitar a amigos que aún no están en Pinterest (pero sí en otras redes sociales) y de buscar amigos que ya lo están.

- El grueso de la página lo ocupa el conjunto de imágenes (pines) de otros pineadores a los que se sigue, del propio usuario y otros pines recomendados para el usuario.

- En el extremo inferior derecho se da la opción rápida de subir y añadir pines, o de crear un nuevo tablero a partir del símbolo +, así como de solicitar ayuda al Centro de Asistencia (a partir del símbolo de interrogación). 




Figura 7. Feed de inicio de Pinterest. Fuente: Pinterest ( http://www.pinterest.com).

\section{Estructura}

La observación de los elementos destacados en el sitio de Pinterest, organizados en torno a la centralidad del pin, arroja las siguientes observaciones en los principales aspectos a analizar de la estructura:

- Origen de las imágenes: pueden subirse desde un ordenador o dispositivo móvil, pero también pueden buscarse en Internet y añadirse instalando el botón Pin it, o lo mismo dentro de la propia página de Pinterest (son los "repines" de otros pineadores).

- Recuperación de las imágenes: además de añadir imágenes previa navegación por Internet, las imágenes pueden añadirse desde el Feed de inicio de Pinterest, buscando por categorías preestablecidas o por palabras clave.

- Clasificación de imágenes: las imágenes son pines y pueden clasificarse en tableros y a través de etiquetas. También pueden señalarse mediante la opción "me gusta" (un corazón). Los tableros pueden ser públicos o privados, individuales o colectivos.

- Funciones de red social: desde Pinterest, se puede seguir o ser seguido por otros pineadores; se pueden compartir, enviar, comentar y denunciar pines, así como marcarlos como "me gusta"; se pueden puntuar pines y tableros (públicamente o por mensaje privado); los pines o tableros pueden compartirse en Facebook.

- Sistema de recomendación: desde Pinterest, las opciones Más de-También estos tableros y pines relacionados sugieren nuevos pines. También hay que tener en cuenta que se avisa de nuevas altas de contactos preexistentes en otras redes sociales, además de si estos contactos te siguen o no. Por correo electrónico, el resumen Pinterest Weekly sugiere Pines nuevos para ti y otros Tableros interesantes. 


\section{TUMBLR}

Se trata de una plataforma de microblogging que permite publicar y republicar textos, imágenes, vídeos, enlaces, citas y sonidos al estilo de un tumblelog o flujo de conciencia.

Existen diversos tipos de medios sociales, entre ellos los blogs o microblogs por una parte, y las redes sociales por otra. Tumblr es un ejemplo híbrido ya que, debido a las opciones de compartir y comentar entradas de blog que ofrece, posee un componente muy destacado de red social.

\section{Datos de negocio}

Tumblr fue fundado por David Karp y Marco Arment en febrero de 2007, y pasó a formar parte del conglomerado Yahoo! Inc en 2013.

Según su información corporativa actualizada, en Tumblr hay casi 220 millones de blogs y se crean más de 88 millones de entradas cada día. La mayoría de los blogs son creados por adolescentes o jóvenes universitarios, así como por profesionales vinculados a la creatividad: diseñadores, publicistas, artistas. Tumblr ocupa la posición 35 en el ranking Alexa y tiene un PageRank de 8/10.

El modelo de negocio se basa en el alta gratuita, pero se obtienen beneficios a través de dos canales principales: las campañas publicitarias dirigidas a un target joven (el perfil de usuario predominante en Tumblr) y la venta de temas o plantillas (themes) para personalizar cada blog.

\section{Elementos visualles}

Los elementos principales que destacan en Tumblr son los propios de cualquier blog, junto con los añadidos de red social, que pueden resumirse en:

- El Escritorio

- La publicación "reblogueable"

- Las opciones de exploración

\section{El Escritorio}

El Escritorio o página de inicio de Tumblr para cada usuario está protagonizada por las publicaciones o posts, propios o ajenos, y por las opciones de búsqueda y seguimiento de blogs:

- En la columna horizontal superior destaca la opción de publicar las entradas propias en distintos formatos: texto, foto, cita, enlace, chat, audio, vídeo (combinados o no)

- La columna vertical central que hay debajo de las opciones de publicación presenta las últimas publicaciones, tanto propias como de los usuarios que se siguen.

- A la derecha del marco superior hay cuatro iconos: casa o inicio de escritorio; brújula u opciones de exploración; sobre o acceso al correo, y el de administración de la cuenta con la figura de una persona. Junto a ellos hay una barra para "Buscar en Tumblr", y el icono de un lápiz para redactar rápidamente una nueva publicación.

- En el marco derecho vertical aparece la información relativa al blog propio: publicaciones, seguidores, 
actividad, borradores y personalizar (edición del tema o plantilla); los datos de cuenta (me gustas y blogs seguidos) y más opciones de búsqueda y recomendación: "Buscar blogs", "Blogs recomendados" (que pueden seguirse fácilmente haciendo clic en el signo +, o ampliarse a "Buscar en todo Tumblr") y Radar (seguir a un usuario recomendado por su popularidad previa).

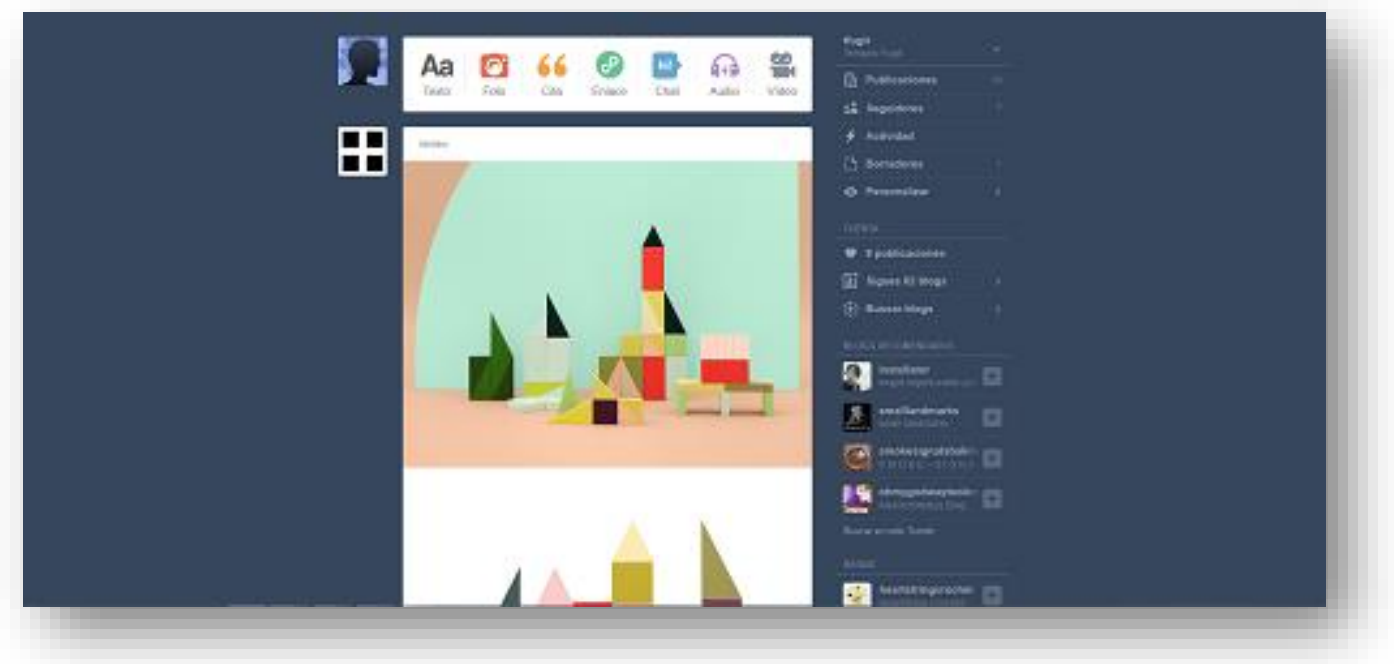

Figura 8. El escritorio de Tumblr. Fuente: Tumblr (https://www.tumblr.com/dashboard).

La publicación "reblogueable"

La publicación o entrada es un elemento híbrido en Tumblr:

- Por un lado se trata de la típica entrada de blog que puede publicarse en uno o varios formatos (texto, foto, cita, enlace, chat, audio, vídeo), siguiendo múltiples opciones de compartir o reblogueo (publicar ahora, añadir a la cola, programar, guardar como borrador, editarla, etc).

- Pero la la publicación también sintetiza las opciones de red social (es decir, "interactuar, compartir e intercambiar información"), pues se pueden rebloguear las publicaciones de otros usuarios en uno o varios formatos, y siguiendo las múltiples opciones de reblogueo existentes. Así, tanto desde del Escritorio como a través de la URL del blog propio que se tenga en Tumblr, no solo aparecen las publicaciones que ha creado originariamente el usuario, sino también aquellas reblogueadas de otros.

Las opciones de exploración

El Escritorio de Tumblr ofrece diversas opciones de exploración para rebloguear contenido:

- La más sencilla es la es caja de búsqueda que permite hacer búsquedas libres.

- Más compleja resulta "Buscar blogs" (en la información de Cuenta), donde se pueden seguir blogs "Destacados", de "Gente a la que conoces" (de Facebook o del correo electrónico), y hacer una búsqueda temática entre casi 60 categorías ordenadas alfabéticamente (de Accesorios a Videojuegos).

- Asimismo, "Buscar en todo Tumblr" (en la sección Blogs recomendados) da acceso a múltiples opciones de búsqueda, sistematizadas en el menú del marco superior que forman Trending 
(populares), Recomendaciones, Staff Picks (propuestas del personal de Tumblr) y según formatos de publicación posibles (donde también se incluyen GIFs). Cada pestaña sugiere diversas publicaciones recomendadas (repartidas en varias columnas, y en ocasiones patrocinadas), así como blogs y búsquedas recomendadas en el marco vertical derecho. El icono Explorar (la brújula) del Escritorio conduce a este mismo menú.

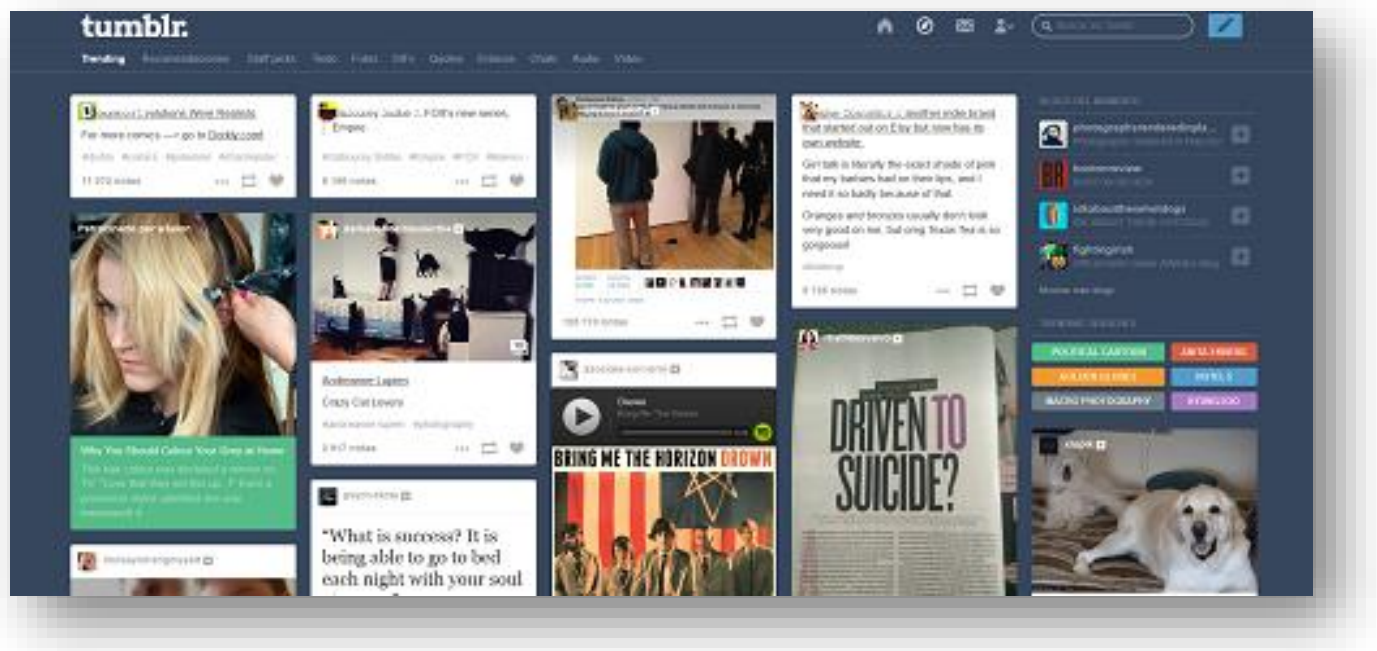

Figura 9. Opciones de exploración de Tumblr. Fuente: Tumblr ( https://www.tumblr.com/explore/trending).

\section{Estructura}

Como en el caso de Pinterest, predominan las imágenes compartidas por otros usuarios en Internet y dentro de la propia red visual (aunque se pueden subir imágenes propias). Pero mientras en Pinterest predomina la idea de crear colecciones de tableros y pines, en Tumblr destaca la instantaneidad de subir y compartir imágenes: el microblogging viral.

Veamos cómo se articula en distintos aspectos:

- Origen de las imágenes: se pueden subir desde el ordenador, copiarse y pegarse procedentes de Internet, o rebloguearse de otros usuarios (opción mayoritaria por las facilidades que ofrece la página para ello).

- Recuperación de imágenes: en el Escritorio desde el buscador, a través de los blogs seguidos, recomendados, o de la opción Radar (blog recomendado especialmente popular). Y tanto desde Buscar en todo Tumblr como desde Explorar, según imágenes populares, recomendaciones, propuestas por el personal, o según formatos.

- Clasificación de imágenes: las publicaciones pueden ser propias o ajenas (reblogueadas); se puede indicar me gusta (corazón) y usarse etiquetas.

- Funciones de red social: se sigue a otros usuarios y se tienen seguidores. Se pueden rebloguear, marcar con "me gusta" y comentar publicaciones con las mismas prestaciones que el blog propio. Las 
publicaciones pueden compartirse en Facebook, Twitter y por correo.

- Sistema de recomendación: en el Escritorio, de manera directa, mediante Blogs recomendados y Radar. A partir de buscar blogs se sugieren usuarios destacados, conocidos, o con afinidades temáticas. Desde Buscar en todo Tumblr y desde el icono de Explorar se ofrecen recomendaciones populares, del personal de Tumblr y según formatos de publicación. Por correo, se propone Explora los temas del momento y otras campañas (de periodicidad semanal, quincenal, etc).

\section{INSTAGRAM}

Se trata de una aplicación móvil y red social para compartir fotografías y vídeos, generalmente creados por los propios usuarios, aprovechando un abanico de herramientas de retoques y filtros fáciles de usar.

Mientras en Pinterest y Tumblr se enfatiza el uso de imágenes ajenas (que pueden ser fotografías, pero también gráficos o ilustraciones, así como vídeos), en Instagram se resalta la creación y el compartir fotografías y vídeos creados por el usuario, de móvil a móvil.

Mientras Pinterest ordena la información visual para coleccionarla y Tumblr para compartirla,

Instagram ha instaurado un formato fotográfico y una interfaz que invitan a señalar con "me gustas" las imágenes preferidas sin detenerse demasiado en cada una de ellas.

Pinterest y Tumblr tienen versiones para móvil, pero son redes pensadas mayoritariamente para la comodidad de navegación web o en tableta. Por su parte, es posible consultar el perfil propio de Instagram en la web mediante aplicaciones externas, pero las acciones propias de red social han de realizarse desde el móvil.

\section{Datos de negocio}

Kevin Systrm y Mike Krieger fundaron Instagram en 2010. Facebook, Inc compró Instagram en 2012. Los 300 millones de usuarios actuales de Instagram se encuentran repartidos de manera equitativa entre los sistemas operativos iOS y Android. La mayoría de los usuarios son urbanos y jóvenes. Instagram ocupa la posición 32 en el ranking Alexa y tiene un PageRank de 9/10.

El modelo negocio se basa en el alta gratuita y muchas empresas lo utilizan como escaparate virtual (aunque no para generar colecciones de productos como Pinterest), para incrementar mediante la sucesión de fotografías el branding o engagement con una determinada marca. Otra cuestión relevante (y controvertida) es el uso que de los datos de usuarios y sus fotografías hacen las empresas de marketing.

\section{Elementos visualles}

Estos elementos corresponden al menú constante que aparece en la parte inferior de la aplicación, es decir:

- Inicio (icono casa)

- Buscar (icono lupa)

- Cámara (icono cámara)

- Actividad (icono corazón)

- Perfil (icono persona) 
Inicio

En el apartado de inicio de Instagram se pueden consultar e interactuar ("me gustas", añadir comentarios) con las últimas fotos subidas, propias o ajenas, tocando la pantalla.

\section{Buscar}

Se presentan varias opciones de búsqueda:

- Por fotos (o vídeos): Instagram presenta en mosaico las fotos o vídeos que se han publicado más recientemente. Al hacer clic sobre cada imagen, se indica por qué ha aparecido: es probable que sea popular en el país del usuario, o que interese según las personas que se siguen.

- Por personas: se indican aquellos contactos de otras redes sociales a los que aún no se sigue en Instagram, o los personajes más populares.

- Búsqueda libre: se hace introduciendo el texto que se desee (con o sin la almohadilla que identifica las etiquetas o hashtags) en el espacio de búsqueda que aparece en la parte superior de la pantalla.



Figura 10. Los resultados más recientes de fotos (resaltado en azul) que aparecen en la opción Buscar de Instagram. También Se puede buscar por personas (en negro) o desde la caja superior. Fuente: cuenta Instagram personal de Raquel Herrera. 


\section{Cámara}

Instagram se conecta a la cámara del smartphone para hacer fotos o vídeos, o para buscarlas en el álbum de imágenes del dispositivo. Antes de subir definitivamente una imagen a la aplicación, existen múltiples opciones para editarla, equivalentes a las de cualquier software de retoque fotográfico (girar, enderezar, contrastar, realzar, iluminar, enfocar o desenfocar; etc.), así como 25 filtros propios de Instagram para lograr efectos diversos en la imagen final.



Figura 11. Ejemplos de edición de fotografías en Instagram añadiendo algunos de los filtros predefinidos por la aplicación. Fuente: cuenta Instagram personal de Raquel Herrera.

\section{Actividad}

En la sección de Actividad aparecen las notificaciones de la cuenta, tanto relativas a usuarios seguidos como al propio usuario: "me gustas", nuevos seguidores, nuevas altas de contactos de otras redes sociales, etc. 


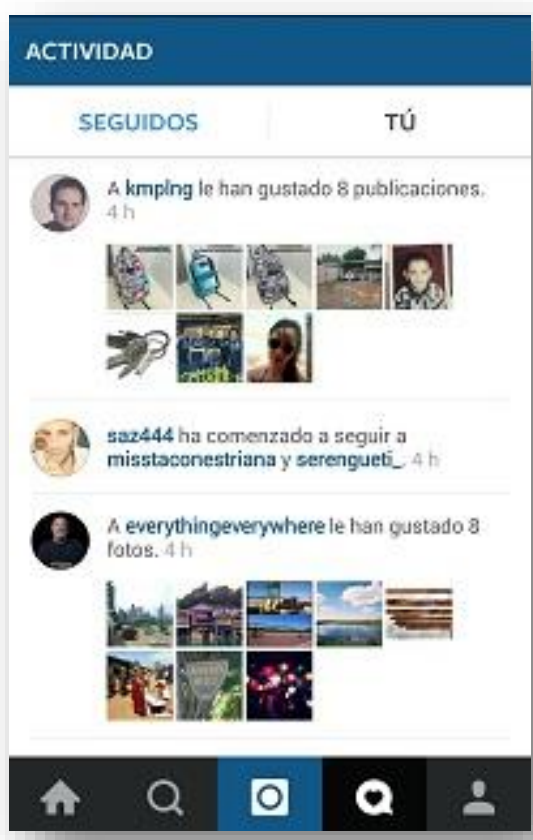

Figura 12. Ejemplo de actividad reciente de los usuarios que se siguen en Instagram. Fuente: cuenta de Instagram personal de Raquel Herrera.

\section{Perfil}

En el perfil se indica el recuento de publicaciones, seguidores y usuarios seguidos, así como la opción de editar el perfil en términos de foto y descripción.

Las fotos propias pueden consultarse en mosaico o individualmente, localizarse y consultarse como un mapa. También desde aquí se consultan las fotos donde el usuario ha sido etiquetado.

Esta sección se amplía haciendo clic en la esquina superior derecha. A partir de aquí se accede a opciones de búsqueda de amigos (Sigue a otras personas) donde destacan las Sugerencias para ti, o contactos de otras redes sociales, así como el histórico de Publicaciones que te han gustado.

En esta último subsección aparecen opciones de configuración de los distintos apartados de la aplicación (cuentas enlazadas, notificaciones de inserción, cámara, vídeos y guardar fotos originales), ayuda, información de la aplicación (blog, privacidad, condiciones del servicio, bibliotecas de código abierto) y cambios en la cuenta (borrar historial de búsqueda, cambiar foto de perfil y salir).

\section{Estructura}

Como hemos adelantado, y a diferencia de Pinterest y Tumblr, la subida de imágenes propias y el uso exclusivo del móvil determinan la estructura de Instagram en términos de subir, gestionar y compartir imágenes. Concretamente: 
- Origen de las imágenes: se pueden subir desde el móvil o hacerlas desde el icono de la cámara. Se pueden compartir de otros usuarios pero con software adicional, no es una opción propia de la aplicación en sí.

- Recuperación de las imágenes: el icono de explorar permite hacerlo por usuarios, etiquetas o libremente.

- Clasificación de las imágenes: viene determinada por los perfiles de usuario, el uso (generalizado) de etiquetas y las indicaciones de localización y geoetiquetado.

- Funciones de red social: se sigue a usuarios y se tienen seguidores. Se pueden comentar y etiquetar fotos propias y ajenas (pública o privadamente, por Direct). Las fotos pueden compartirse por Facebook, Twitter, Tumblr y Flickr, o copiarse externamente su URL. Existen perfiles web, de consulta solo, para cada usuario (por ejemplo Extragram).

- Sistema de recomendación: al Buscar aparecen recomendaciones basadas en usuarios que se siguen o popularidad en el país propio. En el Perfil, la búsqueda de amigos ofrece sugerencias de contactos procedentes de otras redes sociales. Como en Pinterest, se avisa cuando estos contactos se dan de alta en Instagram.

\section{DOCUMENTACIÓN AUDIOVISUAL, SEO Y RSV}

Anteriormente, a través de las definiciones de trabajo, señalamos que el SEO consiste en el conjunto de actividades cuyo objetivo es mejorar la visibilidad de las páginas web a través de los motores de búsqueda. Es sabido que, en los últimos años las redes sociales en general representan un componente fundamental en el SEO. Dicho en el lenguaje especializado del SEO: constituyen uno de los factores principales de actuales de posicionamiento, dado el incremento que, las llamadas señales de usuario, tienen para los algoritmos actuales de posicionamiento de los buscadores.

La cuestión que nos interesa en este trabajo en relación al SEO es la influencia creciente y positiva que las RSV tienen en el SEO según avanzamos en el Diagrama 1. En particular, el efecto que tienen las RSV en el SEO se articular alrededor de tres puntos: (1) branding o credibilidad, (2) tráfico o visibilidad, (3) conectividad o hipertextualidad. Desarrollamos estas tres dimensiones a continuación.

\section{- Branding}

El aspecto de branding está relacionado, como indica el término, con el enorme aporte que una documentación audiovisual de calidad aporta al reconocimiento de una empresa u organismo. Si tal organismo es capaz de desarrollar una política de RSV adecuada, además de reconocimiento, o como un efecto derivado, su presencia en tales redes puede contribuir de forma decisiva a su credibilidad o prestigio.

\section{- Tráfico}

Suele decirse que algunas RSV aportan poco o nada al SEO porque o bien no utilizan enlaces de salida (Pinterest) o bien los enlaces suelen ser de tipo no follow. El problema de esta visión es que no considera cómo es el SEO actual, sino que sigue anclado en la visión antigua del denominado PageRank. Actualmente, no solamente no es un problema tener enlaces de entrada de tipo no follow sino que se considera imprescindible, precisamente por una cuestión de credibilidad. Además, lo que aportan estas redes son, por un lado, tráfico y por el otro señales sociales, en este último caso en 
forma de las métricas de cada RSV (por ejemplo, "seguidores" o "republicaciones". La cuestión es que actualmente tráfico y señales sociales son dos de los factores más potentes en el SEO.

- Hipertextualidad

Con este factor nos referimos a un aspecto que hemos señalado también con el anterior, por tratarse en realidad de un aspecto relacionado con el mismo, pero que necesita tratarse aparte. Dos de las RSV consideradas presentan la posibilidad de establecer enlaces y capas de hipertextualidad de diversos tipos. En primer lugar, tanto en Tumblr como en Pinterest es posible asociar cada una de estas plataformas con otros sitios. El caso de Pinterest es especialmente significativo porque permite esta opción a un nivel doble: cada cuenta en Pinterest puede estar asociada a un sitio web, incluso con la posibilidad de solicitar la autenticación del mismo. Además, cada pin de cada tablero puede establecer enlaces con secciones de uno o más sitios.

Ahora bien, cuando consideramos aspectos de SEO vinculado con las RSV estamos en realidad tratando la necesidad de optimización nuestra presencia en la propia RSV de que se trate en cada caso, ya que de lo contrario de poco servirá la conexión de la misma con el sitio que queremos optimizar, al que denominaremos sitio destino. Por ejemplo, supongamos un escenario en el cual un museo desea aprovechar parte de su documentación multimedia y a tal fin decide crear una cuenta en Pinterest. El sitio del museo es el sitio destino en este caso. Entonces, solamente si la cuenta en Pinterest presenta métricas de éxito (visitas, número de seguidores, repines, etc.) podrá ser útil al SEO del sitio destino (el museo).

A partir de estas consideraciones, para optimizar nuestra presencia en a RSV podemos seguir unas pautas fuertemente similares a las que adoptaríamos para optimizar un sitio web genérico, pero adaptado a la vez a la especificidad de las RSV. Esto se traduce en las siguientes medidas de tipo general:

- Elegir el tema o temas de forma estratégicamente vinculado con los objetivos, la misión, la visión y el público del sitio.

- Elegir un título de cuenta optimizado con la línea anterior

- Publicar siempre contenidos de la máxima calidad posible

- Mantener un calendario equilibrado de publicaciones

- Optimizar todos y cada una de las posibilidades de meta información que estas redes ofrecen. En particular, se debe optimizar los títulos, las palabras clave, las descripciones y, si la red dispone de ellos, los hashtags de cada uno de los posts o publicaciones individuales

- Optimizar la página del perfil de la cuenta, ofreciendo información sobre el sitio destino y, por supuesto, estableciendo un enlace hipertextual a la misma. Por supuesto, esto implica hacer visible la cuenta a los motores de búsqueda, ya que algunas RSV, por ejemplo, Pinterest, permiten mantener los tableros en forma privada. En el caso de Pinterest, además, podemos solicitar la verificación del sitio al que vinculamos la cuenta, lo que añade credibilidad a los tableros. 


\section{CONCUSIONES}

- El número de usuarios creciente y constante que presentan las RSV indica que ocupan un lugar significativo dentro de las redes sociales actuales.

- Asimismo, estudios recientes señalan que crear, comentar y compartir imágenes en redes sociales aumenta la implicación (engagement) de los usuarios.

- Pinterest supone una RSV de referencia para descubrir imágenes de interés, clasificadas por pines y tableros.

- Tumblr supone una RSV de referencia para la inspiración creativa, basada en la exploración polifacética de los microblogs creados por sus usuarios.

- Instagram supone una RSVI de referencia para compartir fotografías editadas y etiquetadas en el móvil.

- Aunque las RSV tienen interés intrínseco y valor por si mismas, como hemos intentado argumentar, sirven además para apoyar estrategias de visibilidad, SEO y difusión de contenidos de sitios web intensivos en contenidos

- La vinculación de las RSV con los sitios intensivos en contenidos puede aportar una nueva dimensión de valor a la documentación audiovisual en particular y la documentación multimedia en general.

- Los responsables de SEO de los sitios intensivos en contenidos pueden tener, en las RSV un aliado de primer orden para la optimización de los mismos.

- Al mismo tiempo, los responsables de documentación de organismos o empresas que generan contenidos audiovisuales pueden poner en valor su actividad colaborando con el SEO de sus instituciones utilizando de forma creativa las RSV. Con esta actividad, además, realizarán una aportación de valor universal, dado el interés de los ciudadanos por la clase de contenidos que sitios como museos, medios de comunicación y universidades pueden poner al alcance público en la Web. 


\section{REFERENCIAS BIBLIOGRÁFICAS}

Nota: todas las referencias en línea se revisaron el día 3 de septiembre con motivo de la última revisión de este trabajo.

3 reasons to use Pinterest in 2015 http://www.searchenginejournal.com/3-reasons-usepinterest-2015/122473/

12 Clever Visuals to Use More Visuals on Social Media http://blog.hubspot.com/marketing/visual-content-social-media-tips

About Twitter https://about.twitter.com/

Castells, M. “Redes”. En Comunicación y poder. Madrid, Alianza: 2009, pp. 45-50.

Equipo Tumblr http://equipo.tumblr.com/

Facebook: 10 years of social networking, in numbers

http://www.theguardian.com/news/datablog/2014/feb/04/facebook-in-numbers-statistics

Facebook Newsroom: Company Info http://newsroom.fb.com/company-info/

Kaplan, Andreas M. y Haenlein, Michael. "Users of the world, unite! The challenges and opportunities of Social Media!”. Business Horizons, no 53, pp. 59-68, 2010

http://www.slideshare.net/escpexchange/kaplan-haenlein-users-of-the-world-unite-thechallenges-and-opportunities-of-social-media

Leading social networks worldwide as of December 2014, ranked by number of active users http://www.statista.com/statistics/272014/global-social-networks-ranked-by-number-ofusers/

List of virtual communities with more than 100 million active users

http://en.wikipedia.org/wiki/List of virtual communities with more than 100 million acti ve users

O’Reilly Media. What is Web 2.0.? http://www.oreilly.com/pub/a/web2/archive/what-isweb-20.html

Observatorio Tecnológico del Ministerio de Educación Cultura y Deporte. Definición de redes sociales

http://recursostic.educacion.es/observatorio/web/ca/internet/web-20/1043-redessociales?start $=1$ 
Freixa, Pere; Sora, Carles; Soler-Adillon, Joan; Ribas, J. Ignasi. "Snow Fall and A Short History of the Highrise: two approaches to interactive communication design byThe New York Time". Textual \& Visual Media, n. 7, 2014, p.63-84. http://textualvisualmedia.com/images/revistas/07/articles/snow fall.pdf

Photos Cluttering your Facebook Feed? Here's why http://www.emarketer.com/Article/Photos-Cluttering-Your-Facebook-Feed-HerersquosWhy/1010777/1

Pinterest has 70 million users. More than $70 \%$ are in the US http://semiocast.com/en/publications/2013 0710 Pinterest has 70 million users

Pinterest Press

http://semiocast.com/en/publications/2013 0710 Pinterest has 70 million users

Press Page Instagram http://instagram.com/press/

Tumblr About Us https://www.tumblr.com/about

Tumblr Información de prensa https://www.tumblr.com/press

What fuels a Tweet's engagement? https://blog.twitter.com/2014/what-fuels-a-tweetsengagement

Nota: Este trabajo forma parte del proyecto "Audiencias activas y periodismo. Interactividad, integración en la web y buscabilidad de la información periodística". CSO2012-39518-C04-02. Plan Nacional de I+D+i, Ministerio de Economía y Competitividad (España). 